\title{
Blending Pedagogies in Higher Education
}

Immaculate Kizito Namukasa

Faculty of Education

University of Western Ontario

Elaine Fournier

Faculty of Education

University of Western Ontario

Hiba Barek

Faculty of Education

University of Western Ontario

Mina Sedaghatjou

College of Liberal Arts and Science

Alfred University

\section{Correspondence:}

Immaculate Kizito Namukasa

Inamukas [at] uwo.ca

Keywords: community of practice (CoP), online/digital technology, scholarship, social learning, professional development, collective learning, social cognitive theory, higher education, neoliberal management culture

\begin{abstract}
This paper presents analysis of evidence on the ways in which the connection between technology and scholarship supported a Community of Practice (CoP) for instructors in a faculty of education in Canada. The goal is to reflect on different types of pedagogical practices of CoP members. We discuss the ways in which both social learning and online technology were harnessed to support professional learning. We based the analysis on notions of collective learning and Bandura's (1986) social cognitive theory that inform studies on professional development. The main unit of analysis is the learning community (Wenger, 1998). CoP members jointly analyzed data from aggregated questionnaires, anonymized notes, and audio and textual recordings of selected meetings, resources archived and follow-up reflection by CoP members. The results showed that four pedagogies were most highly ascribed by CoP members: Culturally Responsive Pedagogies (11.63\%; e.g., caring pedagogies, Healing, Global Transformative and Reconciliatory pedagogies), Hands-on and Digital Pedagogies (11.63\%; e.g., Maker Education and Materiality pedagogies), Story Telling Pedagogies (13.95\%; e.g., Deep, Imaginative, Surprise, Participatory, Story Telling and Learners as Curriculum Makers pedagogies), and $21^{\text {st }}$ Century Teaching (16.28\%; e.g., Blended, Digital and Online pedagogies). The findings provide evidence that there is potential in harnessing digital technology for social learning environments within the context of faculty responding to changing higher education institutional factors, including those motivated by the neoliberal management culture.
\end{abstract}




\section{Introduction}

This paper presents analysis on the ways in which the connection between technology and scholarship supported a Community of Practice (CoP) for instructors in a faculty of education. The goal is to reflect on different types of pedagogical practices among members teaching in the department. We discuss the ways in which both social learning and online technology were harnessed to support professional learning (Fournier et al., 2021).

CoPs are groups of people who share a passion for something they do and learn how to do it better as they interact regularly (Wenger-Trayner \& Wenger-Trayner, 2015). Notions of collective situated learning and Bandura's (1986) social cognitive approach inform studies on professional development (e.g., Blanton \& Stylianou, 2009; Darling-Hammond, 2010; DarlingHammond et al., 2017; Farooq et al., 2007; Warr Pedersen, 2017). We adopt pedagogical metaphors such as participation, geographical and basketry metaphors to understand CoP members' expertise (Wenger, 1998) and professional identities (Lave, 2012). Two gaps are noted in the literature: (a) "the lost academic practice of groups of teachers regularly talking about learning and teaching" (McCormack \& Kennelly, 2011, p. 516); and (b) the loss of focus on the affect and its roles in research on teaching (Gibbs, 2013). Studies addressing these two gaps maintain that professional development is built through professional engagement, nurturing mutual trust, and social connectedness.

\section{Our Community of Practice Process}

Our CoP included academics teaching in a faculty of education in Canada. The faculty offers online, onsite, and blended undergraduate and graduate programs. CoP members regularly met to develop, share, reflect on, and refine teaching ideas and experiences. The scholarship of this community was supported by an instructional design unit and a unit that supports teaching. Following Palmer's (2007) advice, CoP members focused on both cognitive and affective aspects of teaching.

\section{Method of Inquiry}

Similar to research on situated practices that draws from social ethnography, our CoP's major unit of analysis is the learning community (Wenger, 1998). The qualitative evidence that we analyze includes aggregated questionnaire data, anonymized notes, and audio and textual recordings of selected meetings, resources archived on site, and follow-up reflection by CoP members.

\section{Results}

CoP members jointly analyzed results, summarized in Table 1, of an electronic needs assessment $(n=12, N=43)$ in which four of over 10 pedagogies listed were most highly ascribed. A few of the subsequent $\mathrm{CoP}$ meetings focused on jointly further categorizing the pedagogies that members used in their teaching.

\section{Table 1}

Needs Assessment Results

\section{Pedagogy of Interest}

Culturally Responsive Pedagogies

Hands-On and Digital Pedagogies

Story Telling Pedagogies

21st Century Teaching
Adherence Percentage

$11.63 \%$

$11.63 \%$

$13.95 \%$

$16.28 \%$

Open/Technology in Education, Society, and Scholarship Association Conference Proceedings: 2021, Vol. 1(1) 1-6 
Members agreed that the pedagogies differed on several dimensions (e.g., space - place change - time). The pedagogies, nonetheless, can be represented by five broader clusters:

1. Design, Hands-on, Maker Education and Materiality pedagogies

2. Blended, Digital, and Online pedagogies

3. Caring, Culturally Responsive, Food and Wellness pedagogies

4. Deep, Imaginative, Surprise, Participatory, Story Telling, and Learners as Curriculum Makers pedagogies

5. Healing, Global Transformative and Reconciliatory pedagogies

The first cluster relates to Hands-On and Digital pedagogies (11.63\%); the second cluster relates to $21^{\text {st }}$ Century Teaching (16.28\%); The third and the fifth clusters align with Culturally Responsive Pedagogies (11.63\%); and, the fourth cluster links with Story Telling Pedagogies (13.95\%).

\section{Emerging Conversations: Pedagogies Interplay}

In one of the CoP meetings, members noticed and discussed a spiral construct of clusters among the different pedagogies. Certain members doodled, other mapped concepts, and yet others sketched as they reflected on the pedagogies interwoven in their teaching. This multimodal engagement supported the clustering of pedagogies shown above. For example, a participant reflected on the role of surprise in embodied pedagogy (see Figure 1). The member emphasized the decision of a teacher when responding to surprises.

\section{Figure 1}

\section{Links Between Pedagogies}

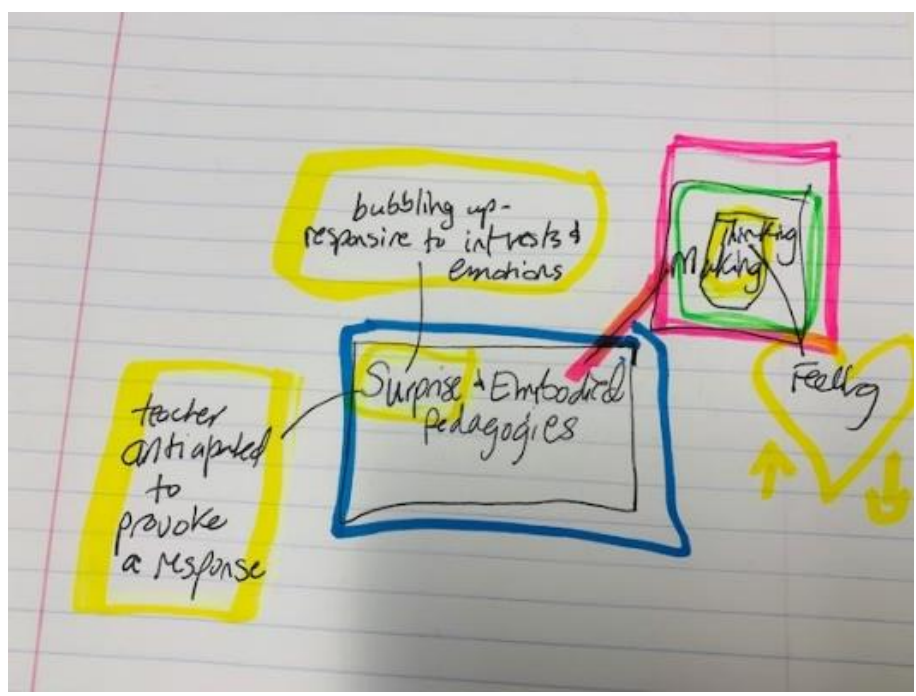

Note. This figure shows a member's reflection on the link between embodied and surprise pedagogies. 


\section{Community of Practice Member Feedback}

Members provided anecdotal feedback on an ongoing basis and had the option to provide follow-up reflections for further research analysis. One member wrote the following narrative:

As an educator who straddles both the academic (research) and practical (principal) world, my actions are driven by my belief in the vital importance of bridging the divide between theory and practice. My desire to learn from and with academic colleagues in the CoP served two key functions; a desire to improve my own practice through participation (self-efficacy) and a desire to contribute to the collective efficacy of the group. Bandura (1997) defined collective efficacy as "a group's shared belief in its conjoint capabilities to organize and execute the courses of action required to produce given levels of attainment" (p. 477). From my lens this given level of attainment would mean an improved level of understanding of theory for the teachers that I support in my field practice and ultimately improved outcomes for their students.

A number of the factors identified by Bandura on group functioning facilitated my meaningful participation in the CoP. First, the CoP's openness to online participation afforded me access to participate in the group despite geographic distance. Second, the leader's consistent communication via email gave me a sense of being in the loop. Third, the various members of the CoP were genuinely interested in one another's professional successes and challenges.

My interactions with the CoP group and one member created new and novel opportunities for me to bridge the theory practice divide. This member's work in technology and mathematics held the potential to directly support our local professional learning community in my field practice. My participation in the CoP supported my instructional leadership and most importantly the professional conversations that found their way to the [school] student desk!

\section{Discussion and Conclusion}

There is potential in harnessing digital technology for social learning environments within the context of faculty responding to changing higher education institutional factors, including those motivated by the neoliberal management culture. Bandura's (1986) social cognitive theory describes the social diffusion of ideas, the acquisition of knowledge, and the adoption of new practices. Bandura also discusses how group functioning is the product of the coordinative dynamics of its members. Some of the factors he describes are the mix of knowledge and competencies of the group, how the group is structured, how its activities are coordinated, how well it is led, the strategies it adopts, and whether members interact with one another in mutually supportive or undermining ways. To Bandura, the structure of social networks affects social diffusion. People are enmeshed in networks of relationships that include kinship, friendships, occupational colleagues and organizational members. They are linked not only directly by personal relationships but also by acquaintances which overlap different networks and landscapes of practices (Wenger, 1998) and, as a result, a variety of people can become linked to one another indirectly by interconnected ties. We see evidence of this network of relationships as a $\mathrm{CoP}$ member further reflects on their experience: 
As a result of my membership in the CoP I had further opportunity to learn from another member about the use of technology to support the instructional dilemma we were facing in my professional practice. This new learning led to a further opportunity to link the CoP member directly to the math lead at my school. Currently we are implementing new approaches to support struggling learners as a direct result of my participation in the CoP.

This linking of individuals and intersections of practices in teacher education, in a faculty learning community, and with educators in $\mathrm{K}-12$, as evidenced by this member's experience with the CoP, became a powerful aspect of the CoP processes.

The connection between technology and scholarship supported the CoP for instructors in our faculty of education in several ways through helping CoP members (a) reflect on the role of technology in their teaching and learning; (b) rethink professional development processes and group functioning and structures; (c) make, design, and repurpose pedagogies and pedagogical content. That said, professional learning in connected communities remains challenged by institutional factors. Thus, conversations on how our institutions are organized in terms of neoliberal management culture and on the widening research and teaching dichotomy cannot be overemphasized.

\section{Author's Contributions}

I.K.N, E.F, H.B, and M.S contributed to the design and implementation of the research, the analysis of the results, the presentation of the OTESSA conference, and the writing of the manuscript.

\section{Open Researcher and Contributor Identifier (ORCID)}

Immaculate Kizito Namukasa (iD https://orcid.org/0000-0001-7231-0671

Elaine Fournier (iD https://orcid.org/0000-0002-1279-5504

Hiba Barek (iD https://orcid.org/0000-0003-3778-6505

Mina Sedaghatjou (iD https://orcid.org/0000-0003-4043-3604

\section{Acknowledgements}

The authors of this study acknowledge the contributions of all CoP members who contributed to our CoP meetings and to this paper.

\section{Funding}

This work was funded by the Centre for Teaching and Learning at Western University, Ontario.

\section{Ethics Statement}

Permission to carry out this research was given by the ethics board at Western University, Ontario.

\section{Conflict of Interest}

The authors have no conflict of interest. 


\section{Data Availability Statement}

Excerpts of original data for this article are only available upon reasonable request from the corresponding author. The authors are unable to publish the data publicly nor grant access to the full sets of the data ethically. This is because the study sample is a small population and participants are potentially recognizable, from anonymized data, by their employer or other employees.

\section{References}

Bandura, A. (1986). Social foundations of thought and action: A social cognitive theory. Prentice Hall. http://www.worldcat.org/oclc/12080269

Bandura, A. (1997). Self-efficacy: The exercise of control. W.H. Freeman and Company. http://www.worldcat.org/oclc/36074515

Blanton, M. L., \& Stylianou, D. A. (2009). Interpreting a community of practice perspective in discipline-specific professional development in higher education. Innovative Higher Education, 34(2), 79-92. https://doi.org/10.1007/s10755-008-9094-8

McCormack, C., \& Kennelly, R. (2011). 'We must get together and really talk ...'. Connection, engagement and safety sustain learning and teaching conversation communities.

Reflective Practice: International and Multidisciplinary Perspectives, 12(4), 515-531. https://doi.org/10.1080/14623943.2011.590342

Darling-Hammond, L. (2010). Teacher education and the American future. Journal of Teacher Education, 61(1-2), 35-47. https://doi.org/10.1177/0022487109348024

Darling-Hammond, L., Hyler, M. E., \& Gardner, M. (2017). Effective teacher professional development. Learning Policy Institute.

Farooq, U., Schank, P., Harris, A., Fusco, J., \& Schlager, M. (2007). Sustaining a community computing infrastructure for online teacher professional development: A case study of designing tapped in. Computer Supported Cooperative Work (CSCW), 16(4), 397-429. https://doi.org/10.1007/s10606-007-9049-0

Fournier, E., Sedaghatjou, M., \& Namukasa, I. K. (2021). Connect to learn: Assemblage of pedagogies in higher education in a community of practice. Open/Technology in Education, Society, and Scholarship Association (OTESSA) Journal. https://journal.otessa.org/index.php/oj

Gibbs, G. (2013). Reflections on the changing nature of educational development. International Journal for Academic Development, 18(1), 4-14. https://doi.org/10.1080/1360144X.2013.751691

Lave, J. (2012). Changing practice. Mind, Culture, and Activity, 19(2), 156-171. https://doi.org/10.1080/10749039.2012.666317

Palmer, P. J. (2007). The courage to teach: Exploring the inner landscape of a teacher's life. (10th anniversary ed.). Jossey-Bass.

Warr Pedersen, K. (2017). Supporting collaborative and continuing professional development in education for sustainability through a communities of practice approach. International Journal of Sustainability in Higher Education, 18(5), 681-696.

https://doi.org/10.1108/IJSHE-02-2016-0033

Wenger, E. (1998). Communities of practice: Learning, meaning, and identity. Cambridge University.

Wenger-Trayner, B., \& Wenger-Trayner, E. (2015). Introduction to community of practice. http://wenger-trayner.com/introduction-to-communities-of-practice

6 Open/Technology in Education, Society, and Scholarship Association Conference Proceedings: 2021, Vol. 1(1) 1-6 